\title{
A comparison between health research output and burden of disease in Arab countries: evidence from Palestine
}

\author{
Loai Albarqouni ${ }^{1 *} \mathbb{D}$, Khamis Elessi ${ }^{2}$ and Niveen M. E. Abu-Rmeileh ${ }^{3}$
}

\begin{abstract}
Background: Research conducted on conditions responsible for the greatest disease burden should be given the highest priority, particularly in resource-limited settings. The present study aimed to assess the research output in relation to disease burden in Palestine and to identify the conditions which are under- or over-investigated, if any.

Methods: We searched PubMed and Scopus for reports of original research relevant to human health or healthcare authored by researchers affiliated with Palestinian institutions and published between January 2000 and December 2015. We categorised the condition studied in included articles using the Global Burden of Disease (GBD) taxonomy. Data regarding burden of disease (percentage of deaths and disability-adjusted life years (DALYS)) was obtained from the Palestine profile in the GBD study. We examined the degree of discordance between the observed number of published articles for each disease/condition with the expected number based on the proportion of disease burden of that disease/condition.
\end{abstract}

Results: Our search identified 2469 potentially relevant records, from which 1650 were excluded following the screening of titles and abstracts. Of the remaining 819 full-text articles, we included 511 in our review. Communicable (infectious) diseases ( $n=103 ; 20 \%)$ was the condition with the highest number of published studies. However, cancer $(n=15 ; 3 \%)$ and chronic respiratory diseases $(n=15 ; 3 \%)$ were the conditions with the lowest number of published studies. Research output was poorly associated with disease burden, irrespective of whether it was measured in terms of DALYs (rho $=-0.116, P=0.7$ ) or death (rho $=0.217, P=0.5$ ). Cardiovascular disease, cancer, and maternal and neonatal deaths accounted for more than two-thirds of the total deaths in Palestine (67\%), but were infrequently addressed (23\%) in published articles.

Conclusions: There is evidence of research waste measured by a mismatch between the health burden of certain diseases/conditions and the number of published research reports on those diseases/conditions in Palestine. A national research priority-setting agenda should be developed to meet the local community's need for quality evidence to implement independent and informed health policies.

Keywords: Health systems research, research agenda, priority-setting, observatory, research and development

\footnotetext{
*Correspondence: Inb6des@daad-alumni.de

${ }^{1}$ Centre for Research in Evidence Based Practice (CREBP), Faculty of Health

Science and Medicine, Bond University, Robina, QLD, Australia

Full list of author information is available at the end of the article
} 


\section{Background}

Palestine, a Middle East and North Africa (MENA) region country, consists of the West Bank, including East Jerusalem, and the Gaza Strip [1]. It has a population of 4.8 million, $42 \%$ of whom are registered refugees - indeed, $26 \%$ and $68 \%$ of those living in the West Bank and Gaza, respectively, are refugees [2]. Over the past decades, Palestinians have undergone a rapid epidemiological transition characterised by a growing burden of non-communicable diseases (NCDs) such as cardiovascular disease (CVD), diabetes and cancer [3].

Palestine, as elsewhere, is facing scarce financial resources and limited research infrastructure, impeding the allocation of adequate resources to health research development [4]. Thus, it is of paramount importance to maximise the utilisation of the, albeit inadequate, resources allocated to health research by prioritising the necessary evidence required by the Palestinian community to develop independent and informed health policies.

Substantial gaps exist between the health research that is needed and that which is conducted, indicating a lack of appropriate prioritisation of health research [5]. In their 2009 Lancet seminal report 'Avoidable waste in the production and reporting of research evidence' [6], Chalmers and Glasziou noted that the dramatic mismatch between questions addressed by researchers and questions of relevance to the community is one of the factors contributing to the estimated $85 \%$ waste in health and medical research. Research prioritisation is therefore required to guide resource allocation to areas of highest priority and to strengthen the links between research, policy and action [7]. There is a need for an accountable, transparent and sustainable approach for research prioritisation on the basis of societal needs (e.g. disease burden) [8]. The burden of disease is a measure that represents the relative impact of different diseases and conditions on population health, and is frequently measured by two indices - mortality (i.e. total deaths) and morbidity (i.e. disability-adjusted life years (DALYs)).

The highest priority should be given to research conducted on conditions that most substantially contribute to disease burden. Topic coverage in research output may serve as a proxy of research prioritisation, with imbalances between the burden of disease and the research output likely indicating specific diseases/ conditions that are relatively under- or overinvestigated compared to their attributable burden. Highlighting this imbalance is therefore critical in providing guidance to stakeholders/policy-makers on the allocation of limited resources in health research. A recent analysis showed a weak association between the global burden of disease and the number of published randomised trials [9]. However, there are no previous studies examining the association between burden of disease and research output in Palestine or in the MENA region. This information can inform policy-makers on the gaps between health research needs and research conducted in Palestine, with implications on research prioritisation, funding allocations and research agenda-setting in Palestine. In this study, we compared the distribution of the output of published health and medical research from Palestine and the distribution of the burden of disease in Palestine and investigated whether specific conditions/diseases are under- or over-investigated.

\section{Methods}

We used the same dataset as in a previous analysis that aimed to assess the quality of reporting of Palestinian medical and health research, but we updated the search till the end of 2015 [10].

\section{Data sources and search strategy}

We searched PubMed and Scopus databases for articles of Palestinian medical and public health studies published between January 1, 2000, and December 31, 2015. We searched for the following terms in the author affiliation, title or abstract: 'palestin",',jerusalem,',west bank', 'gaza', 'oPt', or 'occupied Palestinian territories'. No language restrictions were applied.

\section{Eligibility criteria}

We included all articles of original research authored and/or co-authored by researchers affiliated with Palestinian institutions. We included only articles that reported medical and health studies. We included quantitative studies, whether observational (cross-sectional, cohort, case-control studies, and case series and reports), interventional (controlled trials) or systematic reviews and meta-analyses. We excluded studies where none of the authors was affiliated with a Palestinian institution, even if they included Palestinian participants. We also excluded studies not involving humans as well as studies on health systems research.

\section{Study selection}

Two reviewers independently screened the titles and abstracts of retrieved records against our eligibility criteria. The same two reviewers independently assessed the full texts of all potentially eligible articles. Disagreements between reviewers were resolved by discussion and consensus. Reasons for exclusion were identified and documented. 


\section{Data collection}

Two reviewers independently and in duplicate used a data extraction form to extract the required data from each article, including (1) bibliographic details - authors, journal name, and year of publication; (2) number of authors, the first author's affiliation and any national, regional (i.e. MENA region) or international collaboration; (3) description of disease or condition evaluated according to groups of global burden of disease [11] (in studies tackling more than one disease, we considered the disease relevant to the primary objective of the study, if not reported, then the most highlighted disease throughout the article); (4) sample size (in case of a systematic review and/or meta-analysis, we considered the number of included studies as the sample size); (5) type of study question (prevalence, etiological, diagnostic, prognostic, interventional) and study design (systematic review, randomised controlled trials (RCT), non-randomised intervention study (e.g. controlled trials), cohort, case-control, cross-sectional and case report/ series) [12]; and (6) source of funding (international, local government, academic institution or industry, and not reported/unclear).

\section{Burden of disease}

Data on the burden of disease in Palestine were obtained from the Global Burden of Disease (GBD) 2015 study [13]. GBD is a systematic evaluation and quantification of the burden of major diseases and conditions categorised by age, sex and country. Burden is estimated using both deaths and DALYs [11]. We obtained country-specific estimates of the total number of DALYs and deaths in Palestine for each disease/condition, with death defined as the number of deaths due to a specific cause (disease or injury) within the total population. DALYs is a standardised metric that reflects the discrepancy between existing and ideal health status. DALYs account for both years of life lost due to premature death and years lived with disability.

\section{Data analyses and interpretation}

Descriptive analysis was performed using frequency and percentages. We plotted the total number of research articles for each disease/condition category against their associated deaths (number of deaths per 100,000 population) and DALYs (number of DALYs per 100,000 population). We assessed the correlation between research output and burden of disease using the Spearman correlation test (i.e. Spearman's rho coefficient). We also assessed whether the distribution of research output has matched the distribution of disease burden (i.e. in terms of both deaths and DALYs) for each disease/condition, by examining the degree of discordance between the observed number of published articles for each disease/ condition with the expected/proportionate number of published articles based on the proportion of disease burden for that disease/condition (e.g. the expected number of published articles for CVD $=\%$ of burden caused by CVD $\times$ total published reports $=39.3 \% \times 511=$ 201). The difference between observed and expected number of published articles is expected to be zero when there is a good alignment between research output and disease burden. A positive difference indicates that the disease/condition was over-studied (i.e. research surplus), while a negative difference suggests that the disease/condition was under-studied (i.e. research deficit). We used Microsoft Excel and R software (version 3.2.3) for data preparation and analysis.

\section{Results}

Our search identified 2469 potentially relevant records, from which 1650 were excluded based on screening titles and abstracts. Of the remaining 819 full-text articles, we included 511 in our review. The reasons for excluding the 308 articles were (1) none of the authors/ co-authors was affiliated to a Palestinian institution (36\%); (2) it was an article of qualitative research (34\%); (3) it had not been conducted on individual humans (e.g. basic science research) (16\%); and (4) full texts could not be retrieved (14\%) (Fig. 1).

\section{Characteristics of included studies}

First authors of 361 (71\%) articles were affiliated with Palestinian institutions, 35 (7\%) with regional institutions, and 115 (23\%) with international institutions. Of the 511 included articles, 152 (30\%) involved collaboration between more than one Palestinian institution, 31 (6\%)

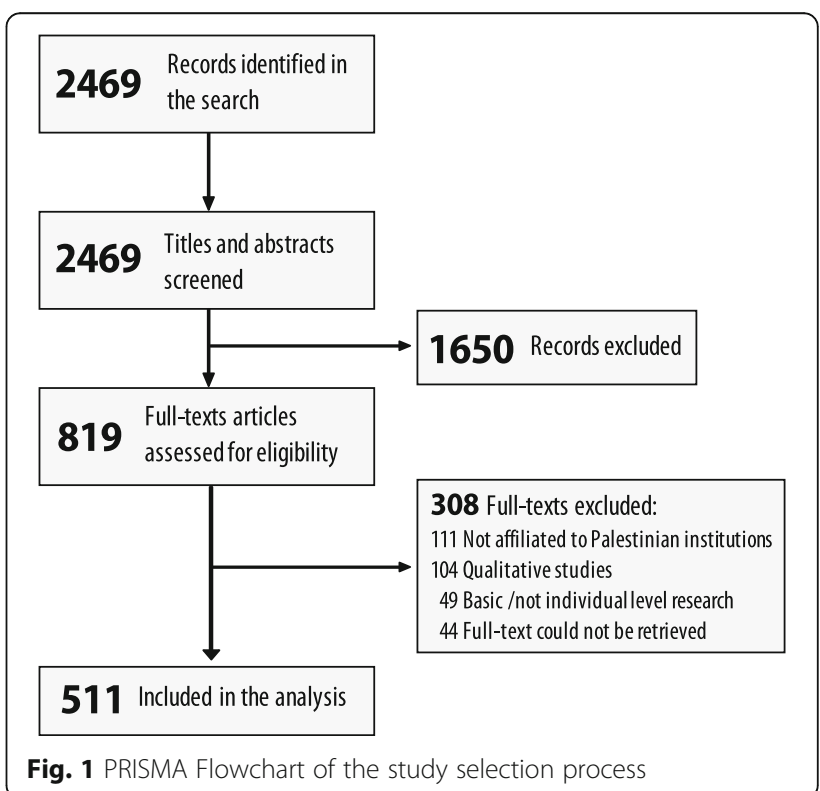


between Palestinian and regional institutions, and 240 (47\%) between Palestinian and international institutions. Most $(371 ; 73 \%)$ of the articles were coauthored by $2-6$ authors.

The number of published Palestinian medical and health research articles increased over time, almost doubling every 5 years (13\% between 2000 and 2004, $32 \%$ between 2005 and 2010, and 55\% between 2011 and 2015).

Table 1 provides information on the general characteristics of the included articles. The most frequent study design was cross-sectional studies $(n=381 ; 75 \%)$, while $16(3 \%)$ were controlled trials, and only $4(0.8 \%)$ were systematic reviews. Most of the articles $(368 ; 72 \%)$ presented prevalence/association studies, 61 (12\%) therapeutic studies, 27 (5\%) aetiological studies, 17 (3\%) prognostic studies, and 11 (2\%) diagnostic studies. The majority of included articles had a sample size of less than 200 participants $(n=406 ; 80 \%)$. Sources of funding were not mentioned in approximately two-thirds (351; $68.7 \%$ ) of the articles. Of those reporting, over twothirds were international $(110 ; 21.5 \%)$.

\section{The distribution of research output and disease burden by disease/condition categories}

The distribution of Palestinian health research output and disease burden (DALYs and deaths) across various diseases/conditions is presented in Table 2. Communicable (infectious) diseases $(n=103 ; 20 \%)$, nutritional diseases $(n=55 ; 11 \%)$, and mental and substance use disorders $(n=54 ; 11 \%)$ were the conditions with the highest number of published studies. However, cancer $(n=15$; $3 \%)$, chronic respiratory $(n=15 ; 3 \%)$, and gastrointestinal diseases $(n=16 ; 3 \%)$ were the conditions with the lowest number of published studies.

Maternal, neonatal and congenital conditions were the main cause of DALYs accounting for $26 \%$ of the total DALYs in Palestine in 2015, followed by cardiovascular (15\%), musculoskeletal and neurological conditions (11\%). CVD, maternal, neonatal and congenital conditions, and cancer were the main causes of death accounting for 39\%, 15\%, and 13\% of the total deaths in Palestine in 2015 .

\section{Association between research output and disease burden}

Cancer, CVD, and maternal, neonatal and congenital conditions were all understudied since they have the highest ratios of disease burden to research output (DALYs per 100,000 population per study: 94.7, 61.9 and 111.6, respectively; deaths 100,000 population per study: 2.7, 2.4 and 1, respectively). However, nutritional, infectious, and mental and substance use disorders were all over-studied with regards to their contribution to the disease burden (DALYs 100,000 population per study: 9.7, 11.4 and 40.1, respectively; deaths 100,000
Table 1 Characteristics of included studies $(n=511)$

\begin{tabular}{|c|c|}
\hline & No. of studies (\%) \\
\hline Total & $511(100)$ \\
\hline \multicolumn{2}{|l|}{ Affiliation(s) of the first author } \\
\hline Palestine & $361(70.6)$ \\
\hline Regional & $35(6.9)$ \\
\hline International & $115(22.5)$ \\
\hline \multicolumn{2}{|l|}{ Collaborations } \\
\hline The same Palestinian institution & $88(17.2)$ \\
\hline Different Palestinians Institutions & $152(29.7)$ \\
\hline Palestinian and Regional Institutions & $31(6.1)$ \\
\hline Palestinian and International institutions & $240(47.0)$ \\
\hline \multicolumn{2}{|l|}{ Number of authors per article } \\
\hline 1 & $53(10.4)$ \\
\hline $2-6$ & $371(72.6)$ \\
\hline$>7$ & $87(17.1)$ \\
\hline \multicolumn{2}{|l|}{ Publication year } \\
\hline 2000-2004 & $68(13.3)$ \\
\hline 2005-2010 & $164(32.1)$ \\
\hline $2011-2015$ & $265(54.6)$ \\
\hline \multicolumn{2}{|l|}{ Sample size (No. of participants) } \\
\hline$<50$ & $187(36.6)$ \\
\hline $50-200$ & $219(42.9)$ \\
\hline$>200$ & $105(20.5)$ \\
\hline \multicolumn{2}{|l|}{ Type of the study question } \\
\hline Prevalence/association & $368(72.0)$ \\
\hline Aetiology/risk factors & $27(5.3)$ \\
\hline Diagnosis & $11(2.2)$ \\
\hline Therapeutic/intervention & $61(11.9)$ \\
\hline Prognosis & $17(3.3)$ \\
\hline Others (case report) & $27(5.3)$ \\
\hline \multicolumn{2}{|l|}{ Study design } \\
\hline Cross-sectional & $381(74.6)$ \\
\hline Systematic review & $4(0.8)$ \\
\hline Randomised controlled studies & $8(1.6)$ \\
\hline Non-randomised interventional studies & $8(1.6)$ \\
\hline Cohort & $38(7.4)$ \\
\hline Case-control & $45(8.8)$ \\
\hline Case reports/series & $27(5.3)$ \\
\hline \multicolumn{2}{|l|}{ Funding sources } \\
\hline Not reported/unclear & $351(68.7)$ \\
\hline Local (governmental/industry/institutional) & $50(9.8)$ \\
\hline International & $110(21.5)$ \\
\hline
\end{tabular}

population per study: 0, 0.2 and 0 , respectively) (Table 2). Figure 2 shows that research output was poorly correlated with disease burden, irrespective of whether measured in 
Table 2 The distribution of research output and disease burden (DALY and death) per disease category

\begin{tabular}{|c|c|c|c|c|c|c|c|c|c|c|}
\hline Disease/Condition & $\begin{array}{l}\text { Research output } \\
\text { (\% total) }\end{array}$ & Rank & $\begin{array}{l}\text { Number } \\
\text { of involved } \\
\text { participants }\end{array}$ & Rank & $\begin{array}{l}\text { DALY rate } \\
\text { per } 100,000 \\
\text { population } \\
\left(\% \text { total DALY) }{ }^{a, b}\right.\end{array}$ & Rank & $\begin{array}{l}\text { Death rate } \\
\text { per } 100,000 \\
\text { population } \\
(\% \text { total death) })^{a, c}\end{array}$ & Rank & $\begin{array}{l}\text { DALY per } \\
100,000 \\
\text { population } \\
\text { per study }\end{array}$ & $\begin{array}{l}\text { Death per } \\
100,000 \\
\text { population } \\
\text { per study }^{\mathrm{a}, \mathrm{e}}\end{array}$ \\
\hline Infectious & $103(20)$ & 1 & 18,101 & 1 & $1170(5)$ & 7 & $18(6)$ & 6 & 11.4 & 0.2 \\
\hline Nutritional & $55(11)$ & 2 & 15,450 & 2 & $536(3)$ & 11 & $0.1(0)$ & 12 & 9.7 & 0 \\
\hline Mental & $54(11)$ & 3 & 13,009 & 3 & $2163(10)$ & 5 & $1.2(0)$ & 11 & 40.1 & 0 \\
\hline Cardiovascular & $52(10)$ & 4 & 9598 & 5 & $3221(15)$ & 2 & $124(39)$ & 1 & 61.9 & 2.4 \\
\hline $\begin{array}{l}\text { Maternal, neonatal } \\
\text { and congenital }\end{array}$ & $50(10)$ & 5 & 6763 & 6 & $5578(26)$ & 1 & $48(15)$ & 2 & 111.6 & 1 \\
\hline $\begin{array}{l}\text { Blood, urogenital and } \\
\text { endocrine diseases }\end{array}$ & $48(9)$ & 6 & 6629 & 7 & $1004(5)$ & 8 & $19(6)$ & 5 & 20.9 & 0.4 \\
\hline $\begin{array}{l}\text { Musculoskeletal and } \\
\text { neurological }\end{array}$ & $37(7)$ & 7 & 1744 & 10 & $2449(11)$ & 3 & $12(4)$ & 7 & 66.2 & 0.3 \\
\hline Diabetes & $36(7)$ & 8 & 11,157 & 4 & $559(3)$ & 9 & $9(3)$ & 9 & 15.5 & 0.2 \\
\hline Injuries & $30(6)$ & 9 & 5779 & 8 & $2314(11)$ & 4 & $28(9)$ & 4 & 77.1 & 0.9 \\
\hline Gastrointestinal & $16(3)$ & 10 & 1454 & 11 & $350(2)$ & 12 & $8(3)$ & 10 & 21.9 & 0.5 \\
\hline Cancer & $15(3)$ & 11 & 864 & 12 & $1420(7)$ & 6 & $40(13)$ & 3 & 94.7 & 2.7 \\
\hline Chronic respiratory & $15(3)$ & 12 & 2559 & 9 & $541(3)$ & 10 & $9(3)$ & 8 & 36.1 & 0.6 \\
\hline
\end{tabular}

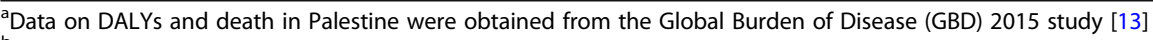

$b_{\%}$ total DALY $=($ DALY rate per 100,000 population for a specific disease or condition $\div$ DALY rate per 100,000 population $) \times 100$; larger value denotes higher contribution of this disease/condition to the total DALY in Palestine

$c_{\%} \%$ total death $=$ (death rate per 100,000 population for a specific disease or condition $\div$ death rate per 100,000 population $) \times 100$; larger value denotes higher contribution of this disease/condition to the total deaths in Palestine

${ }^{d}$ DALYs per 100,000 population per study $=$ (DALY per 100,000 population for a specific disease or condition $\div$ research output for the same disease or condition) $\times 100$

${ }^{e}$ Deaths per 100,000 population per study $=$ (death per 100,000 population for a specific disease or condition $\div$ research output for the same disease or condition) $\times 100$

terms of DALYs (rho $=-0.116, P=0.7$ ) or death $($ rho $=$ $0.217, P=0.5)$.

\section{Expected versus observed research output}

To further assess the association/proportionality between research output and disease burden, we examined the actual observed and expected number of studies as a function of the disease burden (Fig. 3). The difference between the actual and expected number of articles demonstrates whether each condition/disease was under- or over-represented in published Palestinian research articles (0: matched/balanced, negative: understudies/represented:
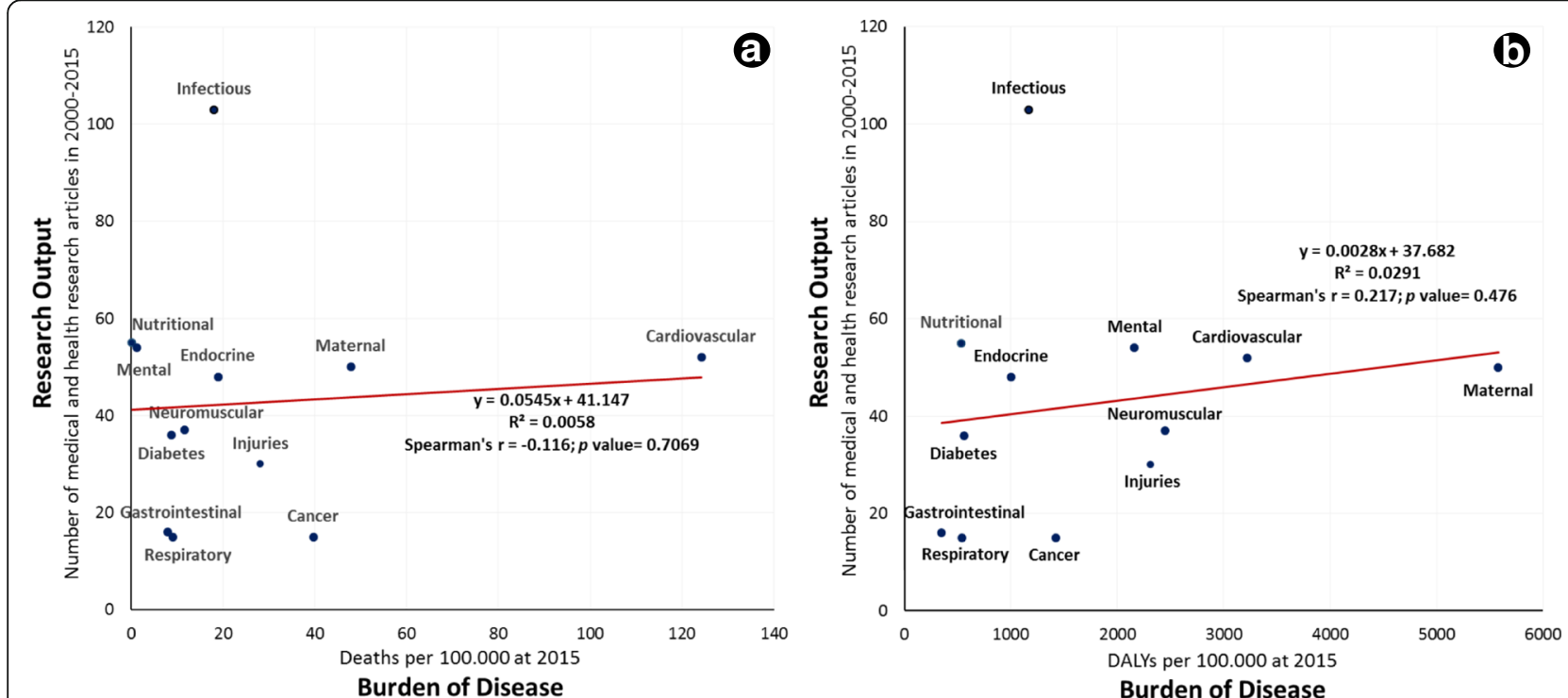

Fig. 2 Relationship between research output (i.e. number of Palestinian medical and health research articles research published between 2000 and 15) and burden of disease as the number of deaths up to 2015 (a) or number of disease-adjusted life years (DALYs) up to 2015 (b) 


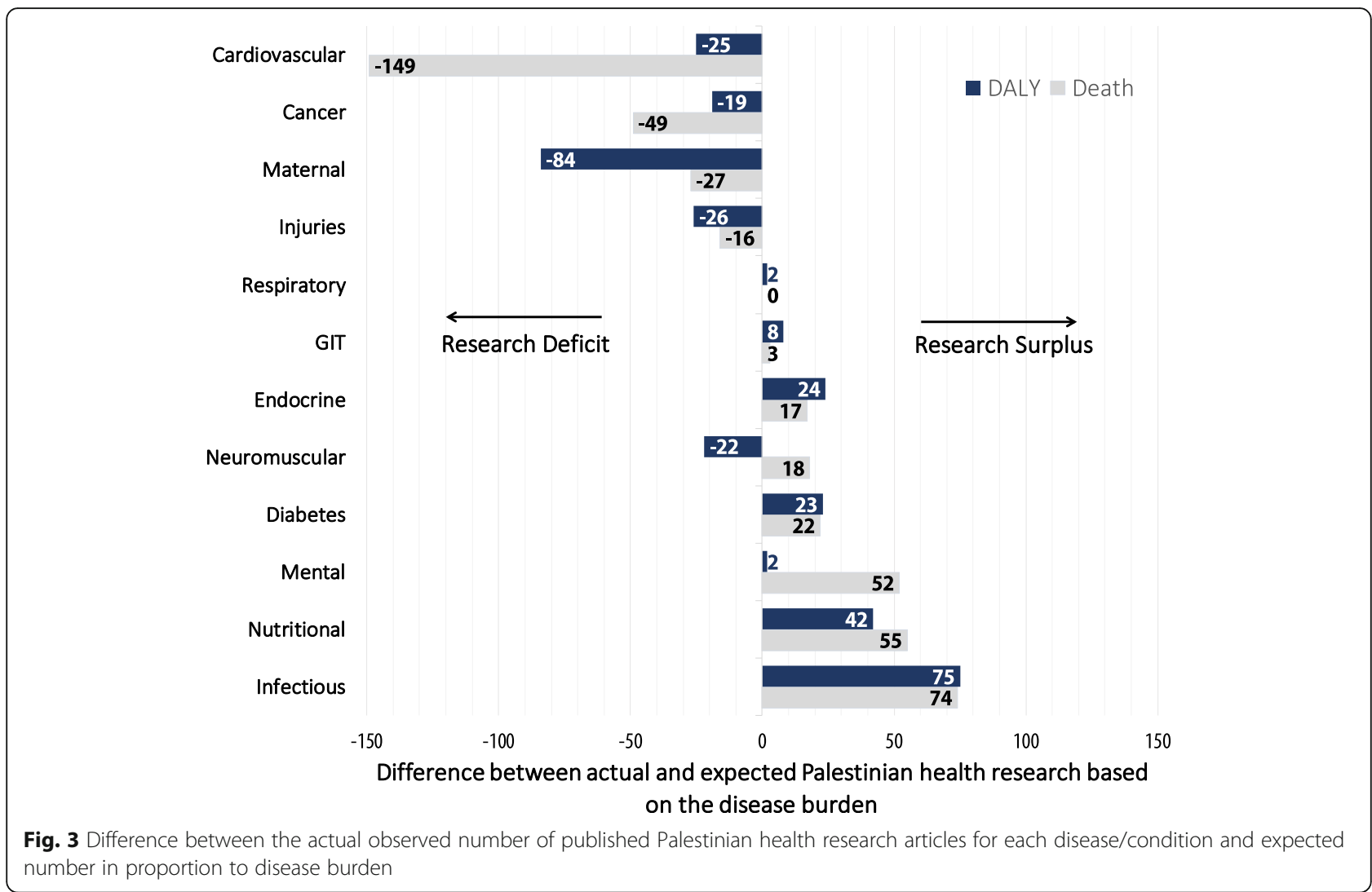

positive: over-studied/represented). Cancer, musculoskeletal diseases, CVD and diabetes were the most understudied conditions relative to their burden, while infectious and nutritional conditions were the most over-studied (Fig. 3).

\section{Discussions}

Our study indicates that there is an evident mismatch between the distribution of disease burden and conditions/diseases that were investigated in published articles from Palestine between 2000 and 2015. It is worrisome that CVD, maternal and neonatal diseases, and cancer account for more than two-thirds of the total deaths in Palestine (67\%), but are infrequently addressed $(23 \%)$ in published articles.

Our findings are in line with a previous investigation of research output (i.e. 66 RCTs published in five leading medical journals) in Latin America that found a poor correlation between disease burden and research output [14]. This was also evident in a recent cross-sectional analysis of 1097 RCTs [9], which found that global burden of disease is poorly associated with the number of published randomised trials (Spearman's $r=0.35 ; P<0.001$ ) as well as with the number of recruited participants (Spearman's $r=0.33 ; P<0.001$ ). Similarly, an analysis of a random sample of 2381 records of trials registered in the WHO's International Clinical Trials Registry Platform (ICTRP), found that there is little correlation between disease burden and the global distribution of registered clinical trials, with research and development not adequately meeting the needs of populations in lowerincome countries [15]. A 2002 study of 1179 published randomised trials from sub-Saharan Africa (48\% from South Africa) showed a good correlation between the estimated burden of disease and the number of trials performed (Spearman's $r=0.53, P=0.024$ ) and the number of participants randomised (Spearman's $r=0.68$, $P=0.002$ ) [16]. However, a recent sub-set analysis of all these RCTs found that a very poor correlation between disease burden and the number of trials (Spearman's $r=0.17$ ) [9]. This can be explained by the rapid epidemiological transition in sub-Saharan Africa, involving an increase in NCD burden, and yet a prioritisation of communicable diseases (e.g. HIV and malaria) in sub-Saharan countries' health research systems and capacity $[17,18]$.

A recent scoping review of 3776 NCD-related reports published between 2000 and 2013 from seven Arab countries [19], found a mismatch between cause-specific death rates and research output, with a relative surplus of reports on cancer and a relative deficit of those on CVDs. The subset analysis of reports from Palestine showed a deficit of studies on both CVDs and cancer. 
However, this study is limited to publications related to NCDs, to the exclusion of other diseases/conditions.

Previous investigations have also shown that there is a mismatch between disease burden and allocated funds. An analysis of the relation between WHO's budgetary allocations and burden of disease found a misalignment between fund allocation and disease burden, with a noticeable skew towards infectious diseases [20]. However, Gross et al. [21] compared the estimates of National Institute of Health disease-specific funding in 1996 with the burden of disease, and found that funding was more strongly associated with DALYs $(r=0.62, P<0.001)$ than the number of deaths $(r=0.40, P=0.03)$.

Important to note is the slight discrepancies between the findings related to comparing research output to death rates and DALYs, respectively. While high case fatality rates for some conditions may inflate death rates (e.g. CVD and cancer), disabling conditions with no cure and long duration (e.g. musculoskeletal and neurological) inflate DALYs. For instance, we found that 'Musculoskeletal and Neurological' and 'Injuries' conditions were understudied when considering DALYs but less so when considering death rates.

The observed discordance between the focus of the published research from Palestine and disease burden can be explained by several factors, including (1) researchers' interest and expertise; (2) limited research infrastructure and funding resources, which drive researchers to accept the funder agenda, not commonly aligned with local community needs [22-24]; and (3) lack of communication between policy-makers and researchers to agree on national research priorities [20, 25].

A limitation to this review is that we only searched two databases (PubMed and Scopus) and we may have therefore missed a number of relevant studies not indexed therein, as well as any unpublished studies. Similarly, excluding lab-based studies may have influenced the results of our study (e.g. cancer studies are frequently lab-based, and therefore more likely missed due to our eligibility criteria). Further, there is some degree of subjectivity in assigning each study to a particular disease or condition. However, two reviewers assigned studies to each category independently and in duplicate. Important to note is that published research output may not necessarily accurately reflect all work being conducted in a particular condition/disease area. Indeed, research output is only one of five core indicators of potential societal benefits of health research, as described by Hanney et al. [26] in their Payback model (i.e. a framework of five core indicators: knowledge production, research targeting and capacity, informing policy, health and health sector benefits, and economic benefits). We also found that the clear majority (96\%) of health research from Palestine were observational studies, which have limited potential to inform health policy-making compared to a higher level of evidence (e.g. systematic reviews and RCTs).

\section{Implications of our findings \\ Establish a national medical and health research priority-setting in Palestine}

Priority-setting is essential for efficient use of limited resources, and an integral step needed in the national research management process to assist the allocation of limited resources to meet national health goals. Otherwise, there is a risk that research topics are determined and imposed by funding organisations for their own agenda and policies.

National research priority-setting should be derived using transparent methodologies, including an evidencebased systematic assessment and situation analysis. Stakeholder involvement in the priority-setting exercise should be inclusive to ensure the extensive participation of researchers, clinicians, university research boards, government, funders, civil organisations, industry, patients and the public. Crowe et al. [27] found a persistent mismatch between patients', clinicians' and the research communities' priorities. In a recent comprehensive assessment of health research priority-setting initiatives in developing countries, McGregor et al. [25] found that the majority of the 91 identified priority-setting initiatives took place at the global level (i.e. those with global health agenda such as eradicating specific diseases) with a developing country focus. However, most did not have any evidence of implementation or follow-up.

\section{Enhance the capacity of national researchers and urge them to conduct prioritised research}

Lack of sufficient health research capacity is still a major barrier to conduct evidence-based health research to inform policy and improve health [28]. The World Health Report 2013 focused on the importance of all nations being producers and consumers of research (i.e. to develop a capacity to not just adopt the evidence, but to adapt it to local circumstances [29]). Therefore, research capacity-building should be given a higher priority and needs to be equally valued as research outputs by development parties [30, 31].

\section{Foster dialogue between researchers, policy-makers, funders and end-users/patients}

Communication between researchers, academics, decisionmakers and patients/public should be started as early as possible during the research priority-setting and continued throughout the research conduction. Further, results dissemination should be fostered by knowledge translation interventions to enhance the uptake of evidence into practice. This exchange of ideas and information will facilitate the bridging of the gap between research 
conducted at research institutions and the community's and decision-makers' needs.

\section{Conclusions}

Despite the encouraging increase in the research output from Palestine over the last decades, there remains a weak association between research output and burden of disease. NCDs (e.g. CVD and cancer) receive much less attention by researchers despite accounting for most of the disease burden in Palestine. National research prioritysetting should be developed to meet the Palestinian community's need for quality evidence to establish independent and informed health policies.

\section{Acknowledgements}

Not applicable.

\section{Funding}

This research received no specific grant from any funding agency in the public, commercial or not-for-profit sectors.

\section{Availability of data and materials}

The datasets used and/or analysed during the current study are available from the corresponding author on reasonable request.

\section{Authors' contributions}

$L A, K E$, and NA conceived the idea. LA searched the literature from electronic databases. LA, KE, and NA participated in data screening, extraction and quality assessment. LA analysed the data and drafted the manuscript. All authors provided critical comments and contributed to the interpretation of analysed results. All authors read and approved the draft. LA is the guarantor of the study.

\section{Ethics approval and consent to participate}

Not applicable.

\section{Consent for publication}

Not applicable.

\section{Competing interests}

The authors declare that they have no competing interests.

\section{Publisher's Note}

Springer Nature remains neutral with regard to jurisdictional claims in published maps and institutional affiliations.

\section{Author details}

${ }^{1}$ Centre for Research in Evidence Based Practice (CREBP), Faculty of Health Science and Medicine, Bond University, Robina, QLD, Australia.

EEvidence-Based Medicine Unit, Faculty of Medicine, Islamic University, Gaza, Palestine. ${ }^{3}$ Institute of Community and Public Health, Birzeit University, Ramallah, West Bank, Palestine.

Received: 5 September 2017 Accepted: 28 February 2018

Published online: 15 March 2018

\section{References}

1. World Bank Definition of MENA: Middle East and North Africa. http://www. worldbank.org/en/region/mena. Accessed 9 Mar 2018.

2. Palestinian Central Bureau of Statistics: Main Statistical Indicators in the West Bank and Gaza Strip. 2015. http://www.pcbs.gov.ps/Portals/_Rainbow/ StatInd/StatisticalMainIndicators_E.htm. Accessed 9 Mar 2018.

3. Husseini A, Abu-Rmeileh NM, Mikki N, Ramahi TM, Ghosh HA, Barghuthi N, Khalili M, Bjertness E, Holmboe-Ottesen G, Jervell J. Cardiovascular diseases, diabetes mellitus, and cancer in the occupied Palestinian territory. Lancet. 2009:373:1041-9.

4. Maziak W. The crisis of health in a crisis ridden region. Int J Public Health. 2009:54:349-55.

5. Rottingen JA, Regmi S, Eide M, Young AJ, Viergever RF, Ardal C, Guzman J, Edwards D, Matlin SA, Terry RF. Mapping of available health research and development data: what's there, what's missing, and what role is there for a global observatory? Lancet. 2013;382:1286-307.

6. Chalmers I, Glasziou P. Avoidable waste in the production and reporting of research evidence. Lancet. 2009;374:86-9.

7. Rudan I, Kapiriri L, Tomlinson M, Balliet M, Cohen B, Chopra M. Evidence-based priority setting for health care and research: tools to support policy in maternal, neonatal, and child health in Africa. PLOS Med. 2010;7:e1000308

8. Viergever RF. The mismatch between the health research and development (R\&D) that is needed and the R\&D that is undertaken: an overview of the problem, the causes, and solutions. Glob Health Action. 2013;6:22450.

9. Emdin CA, Odutayo A, Hsiao AJ, Shakir M, Hopewell S, Rahimi K, Altman DG. Association between randomised trial evidence and global burden of disease: cross sectional study (Epidemiological Study of Randomized Trials-ESORT). BMJ. 2015;350:h117.

10. Albarqouni $L$, Abu-Rmeileh NM, Elessi K, Obeidallah M, Bjertness $E_{\text {, }}$ Chalmers I. The quality of reports of medical and public health research from Palestinian institutions: a systematic review. BMJ Open. 2017;7:e016455.

11. Global Burden of Disease Study 2013 Collaborators. Global, regional, and national incidence, prevalence, and years lived with disability for 301 acute and chronic diseases and injuries in 188 countries, 1990-2013: a systematic analysis for the Global Burden of Disease Study 2013. Lancet. 2015;386:743-800.

12. Study designs. http://www.cebm.net/study-designs/. Accessed 9 Mar 2018.

13. GBD Compare Data Visualization. https://vizhub.healthdata.org/gbdcompare/. Accessed 9 Mar 2018.

14. Perel P, Miranda JJ, Ortiz Z, Casas JP. Relation between the global burden of disease and randomized clinical trials conducted in Latin America published in the five leading medical journals. PLoS One. 2008;3:e1696

15. Viergever RF, Terry RF, Karam G. Use of data from registered clinical trials to identify gaps in health research and development. Bull World Health Organ. 2013;91:416-425C

16. Isaakidis P, Swingler GH, Pienaar E, Volmink J, loannidis JP. Relation between burden of disease and randomised evidence in sub-Saharan Africa: survey of research. BMJ. 2002;324:702.

17. Maher D, Smeeth L, Sekajugo J. Health transition in Africa: practical policy proposals for primary care. Bull World Health Organ. 2010;88:943-8.

18. Maher D, Sekajugo J. Research on health transition in Africa: time for action. Health Res Policy Syst. 2011:9:5.

19. Sibai AM, Singh NV, Jabbour S, Saleh S, Abdulrahim S, Naja F, Yazbek S. Does published research on non-communicable disease (NCD) in Arab countries reflect NCD disease burden? PLoS One. 2017;12:e0178401.

20. Stuckler D, King L, Robinson H, McKee M. WHO's budgetary allocations and burden of disease: a comparative analysis. Lancet. 2008;372:1563-9.

21. Gross CP, Anderson GF, Powe NR. The relation between funding by the National Institutes of Health and the burden of disease. N Engl J Med. 1999:340:1881-7.

22. Sridhar D. Who sets the global health research agenda? The challenge of multi-bi financing. PLoS Med. 2012;9:e1001312.

23. Ijsselmuiden C, Jacobs M. Health research for development: making health research work... for everyone. Scand J Public Health. 2005;33:329-33.

24. Gonzalez-Block MA. Health policy and systems research agendas in developing countries. Health Res Policy Syst. 2004;2:6.

25. McGregor S, Henderson KJ, Kaldor JM. How are health research priorities set in low and middle income countries? A systematic review of published reports. PLoS One. 2014;9:e108787.

26. Hanney SR, Grant J, Wooding S, Buxton MJ. Proposed methods for reviewing the outcomes of health research: the impact of funding by the UK's 'Arthritis Research Campaign'. Health Res Policy Syst. 2004;2:4.

27. Crowe S, Fenton M, Hall M, Cowan K, Chalmers I. Patients', clinicians' and the research communities' priorities for treatment research: there is an important mismatch. Res Involv Engagem. 2015;1:2. 
28. World Health Organization. Research for Universal Health Coverage: The World Health Report 2013. Geneva: WHO; 2013.

29. Hanney SR, Gonzalez-Block MA. Organising health research systems as a key to improving health: the World Health Report 2013 and how to make further progress. Health Res Policy Syst. 2013;11:47.

30. Franzen SR, Chandler C, Lang T. Health research capacity development in low and middle income countries: reality or rhetoric? A systematic meta-narrative review of the qualitative literature. BMJ Open. 2017;7:e012332.

31. Lansang MA, Dennis R. Building capacity in health research in the developing world. Bull World Health Organ. 2004:82:764-70.

Submit your next manuscript to BioMed Central and we will help you at every step:

- We accept pre-submission inquiries

- Our selector tool helps you to find the most relevant journal

- We provide round the clock customer support

- Convenient online submission

- Thorough peer review

- Inclusion in PubMed and all major indexing services

- Maximum visibility for your research

Submit your manuscript at www.biomedcentral.com/submit
Biomed Central 